\title{
De olho no minotauro: a poética do labirinto em tessituras eletrônicas de Andrei Thomaz
}

\author{
Vinicius Carvalho Pereira' \\ https://orcid.org/0000-0003-1844-8084 \\ I - Universidade Federal de Mato Grosso. \\ Cuiabá (MT), Brasil.
}

Resumo: Investigamos neste artigo como a metáfora do labirinto, em íntima relação com outras imagens da complexidade e da interconexão, como a rede e o rizoma, é uma constante em diferentes obras do artista Andrei Thomaz, especialmente naquelas que aqui tomamos como objeto de análise: Dédalo e Ariadne, A caça e o caçador e Biblioteca. Em tais projetos, percebemos uma evidente trama de conexões intertextuais e intermidiáticas, nas quais chamam mais atenção os movimentos de passagens entre esses discursos do que uma suposta especificidade de cada linguagem artística. A metáfora do labirinto serve-nos, pois, de fio de Ariadne com o qual possamos deambular entre os trabalhos de Thomaz e os textos da cultura por eles evocados, de modo a nortear nossa reflexão sobre como muitas dinâmicas hipermidiáticas se estruturam como labirintos. Nestes, com frequência o usuário é convidado a experimentar os sentidos de desorientação e exploração que caracterizam todo dédalo, sob a eterna ameaça de um minotauro, uma dúvida, uma disrupção interpretativa que só tornam o caminho mais interessante.

Palavras-chave: artes digitais; labirinto; hipermídia; Andrei Thomaz.

Abstract: Keeping an eye on the minotaur: the poetics of the labyrinth in electronic textures by Andrei Thomaz - In this paper we investigate how the metaphor of the labyrinth, closely related to other images of complexity and interconnection, such as the network and the rhizome, is a constant in different works by the artist Andrei Thomaz, especially those that we herein embrace as analysis objects: Daedalus and Ariadne, The Hunter and the Prey and Library. In 
those projects, we can see an evident weaving of intertextual and intermedia connections, which draw more attention to the passages between these discourses than to a so-called specificity of each artistic language. Therefore, the metaphor of the labyrinth plays the role of Ariadne's thread, with which we can wander among Thomaz's works and the texts they evoke, so as to guide our reflection on the extent to which many hypermedia dynamics are structured as mazes. In them, the user is frequently asked to experience the senses of disorientation and exploration that are so characteristic of labyrinths, under the threat of a minotaur, a doubt, an interpretive disruption that only makes the pathway more interesting.

Keywords: digital arts; labyrinth; hypermedia; Andrei Thomaz.

\section{Entrando no labirinto}

Diferentes metáforas geométricas já foram empregadas nas humanidades para conceituar dinâmicas pelas quais elementos semióticos - signos, textos ou qualquer coisa a meio do caminho entre essas instâncias - se articulam para constituir relações significativas. Temos círculos hermenêuticos de Gadamer, triângulos de Peirce, quadrados semióticos de Greimas, linhas cronológicas de toda sorte, entre tantas outras formas de expressar conexões de sentido a partir de uma sintaxe visual. A despeito dos distintos pressupostos epistemológicos que subjazem a essas metáforas, notamos um gesto em comum: instituir valor semiótico no que é da ordem do puramente locativo, de modo que as posições relativas de pontos numa figura traduzam articulações de sentido em fenômenos do mundo cultural.

Na segunda metade do século XX, o pós-estruturalismo francês e uma série de outras correntes teórico-críticas que desta derivam, como as relacionadas ao pós-modernismo, passaram a apostar em outras representações topológicas para conceituar operações de significação, sobretudo valendo-se de imagens como as do modelo tabular (KRISTEVA, 1969), do rizoma (DELEUZE; GUATTARI, 1997), da complexidade (MORIN, 2007) e da rede (MUSSO, 2004).

Todas essas metáforas, que visam a dar conta dos cada vez mais intrincados processos comunicativos que vivemos, principalmente após o boom das tecnologias digitais e da globalização, têm em comum uma concepção da significação como advinda de agregados de elementos conectados de forma cruzada, densa e complexa, entre os quais podem ser traçados variados percursos. Em tais conjuntos reticulares, observam-se também dinâmicas locais que afetam fenômenos globais e vice-versa, mas sem que haja necessariamente um isomorfismo entre os níveis macro e micro, dada a multiplicidade 
dos possíveis arranjos entre seus elementos constitutivos. Muito próximas dos labirintos, essas metáforas conceituais implicam espaços topológicos, nos quais o que importa são os traçados das conexões, e não as superfícies que os pontos eventualmente formam (MOREIRA, 2012) ou as distâncias absolutas entre eles. Assim, noções como perto e longe deixam de ter referenciais métricos e passam a ser pensadas em termos de quantidades de links entre nós a serem atravessados.

Sendo essa a lógica que preside também ao hipertexto e à hipermídia (MACHADO, 1997; SNYDER, 1997; LEÃO, 2005; MOREIRA, 2012) - e, por extensão, à internet - , tais metáforas tornam-se tropos recorrentes para a discussão de artefatos desenvolvidos no bojo da cultura digital, entre os quais destacamos, no presente artigo, as escrituras artísticas em meio eletrônico. Como qualquer prática que tem por horizonte precípuo a estética, a ciberarte se interroga quanto às estruturas constituintes de sua mensagem; no caso, a organização labiríntica de seus signos, acessíveis a partir de variados pontos de entrada no sistema.

Nesse contexto, parece-nos uma empreitada importante para as humanidades hoje analisar como diferentes projetos artísticos na internet tematizam os processos de significação reticulares que a metáfora do labirinto enseja. Para tanto, este artigo tem por objetivo o estudo das diferentes apropriações desse tropo em três obras digitais de Andrei Thomaz — Dédalo e Ariadne, $A$ caça e o caçador e Biblioteca —, artista visual cujo portfólio inclui uma série de trabalhos em que o labirinto figura nos planos da expressão e do conteúdo em diversas tessituras eletrônicas ${ }^{1}$. Na próxima seção, procedemos a uma mirada panorâmica sobre o tratamento dessa metáfora em diferentes linguagens, como as artes visuais, os jogos e a literatura, as quais são revisitadas nos trabalhos supracitados de Andrei Thomaz. Por último, apresentamos as considerações finais e as referências que nortearam a condução desta pesquisa.

\section{Escolhendo caminhos e trilhando percursos}

Correntes teórico-críticas frequentemente revisitam conceitos do passado sob nova roupagem: reeditada em discursos acadêmicos das últimas décadas 
do século XX, a figura do labirinto é fundante no imaginário do mundo ocidental enquanto arquétipo associado a semas como o desafio, a travessia, a complexidade, a interconexão. Sua expressão mitológica mais conhecida - matriz de que se deriva toda uma rede de narrativas em outras mídias - é a do labirinto de Cnossos, na ilha de Creta, construído por Dédalo (donde o uso do substantivo dédalo como sinônimo de labirinto) a mando do rei Minos. Encerrando em suas profundezas o monstruoso minotauro, a intrincada obra arquitetônica condenava os encarcerados a vagarem eternamente ao longo de seus túneis, até que se defrontassem com a furiosa besta, sem possibilidade de escapatória. Como bem sabemos, só três homens míticos obtiveram êxito em sua fuga: Dédalo e seu filho, Ícaro, por excurso a pares de asas feitos com ceras de abelha e penas de aves, para alçar voo e transpor pelos ares as paredes do labirinto, o qual não dispunha de teto, segundo diversos relatos (MACHADO, 1997; LEÃO, 2005); e Teseu, ao valer-se do fio de Ariadne para guiar sua exploração e, após matar o minotauro, encontrar uma porta de saída. Conforme veremos mais à frente, tais heróis personificam estratégias tecnológicas diferentes para abordar o problema do labirinto, as quais podem culminar também em distintas representações desse tropo nas artes digitais.

A aproximação entre essa imagem mítica e as tessituras eletrônicas pode ser feita por várias perspectivas - e eis-nos de novo diante de uma organização rizomática ou reticular, com diferentes pontos de entrada, saída e interconexões, mas agora de genealogias em múltiplos regimes semióticos. Brunel (2000, p. 556) afirma que o labirinto é "uma metáfora sem referente", dado que não há, de fato, nenhum labirinto a priori no mundo, senão representações sígnicas do conceito de labirinto. Sem um esteio específico no real, essa ideia acaba tomando as mais diferentes feições para cada sociedade e seu tempo:

Cada um deles parece formar uma certa imagem do labirinto, ou melhor, parece servir-se dessa metáfora para figurar uma tensão fundamental à condição humana. A Antiguidade, por exemplo, o uno e o múltiplo. A Idade Média, a horizontalidade e a verticalidade. A Renascença (séculos XIV a XVI), o exterior e o interior. A época clássica (séculos XVII e XVIII), a realidade e a aparência. A época moderna, o finito e o infinito. (BRUNEL, 2000, p. 556)

2 Segundo Leão (2005), é significativa também a etimologia do onoma: a forma grega daidalos, de que se deriva Dédalo, indica obreiro astucioso, criativo, engenhoso, hábil, em evidente relação com o laborioso ofício de construção do labirinto. 
No âmbito das artes visuais, a dialética entre esses pares comparece de modo variado em pinturas rupestres, moedas minoicas, mosaicos bizantinos, pinturas renascentistas, jardins clássicos, planos urbanísticos modernos, casas de espelhos em parques de diversões e o que o valha, tecendo-se uma verdadeira trama de especulações sobre o labirinto ao longo da história da humanidade. Tal metáfora acaba por ganhar novas potencialidades na mídia eletrônica, em que a arquitetura hipertextual e as organizações em rede promovem maiores dinâmicas reticulares, os recursos de computação gráfica permitem figurações geométricas até então impensáveis, e os dispositivos de realidade virtual ensejam experiências imersivas em espaços de complexa e intrincada topologia. Segundo White (1997, p. 48), o computador em si mesmo é um labirinto, tanto em termos de armazenamento de dados quanto na sua lógica de loops de feedback; não deve, pois, ser entendido como ferramenta, mas como "'o espelho deformante da casa dos espelhos' (fun-house mirror), o que nos remete à capacidade que o 'computador' tem de absorver nossa intenção e jogá-la de volta para nós como uma metamorfose surpreendente". Já Machado (1997) nos lembra que a organização labiríntica do computador é uma amplificação do próprio desenho dos chips, também formados por intrincados circuitos.

Por sua vez, Tavares (2010) mapeia genealogias de labirintos textuais desde jogos poético-visuais da Antiguidade Greco-Romana, passando pela Idade Média, pelo barroco ibérico, pela poesia experimental portuguesa, pela poesia concreta brasileira e culminando hoje na poesia digital ${ }^{3}$. Como fio condutor entre essas manifestações, Tavares (2010, p. 20) destaca "uma tradição da experiência e de engenho, uma tradição procedural". Esta postula uma apreciação ativa, geralmente exigindo do leitor que primeiro reconheça uma sequência não óbvia de passos a partir dos quais um objeto não convencional possa ser compreendido como texto; isto é, que o leitor reconstitua o mapa do labirinto sígnico que culminaria num todo legível. Só depois dessa operação algorítmica de abstração pode-se de fato ler uma escritura que, como dédalo, seja procedural. Nesse diapasão, tanto o ato

3 Considerando a amplidão do tema e a proficuidade da imagem do labirinto nas artes e na literatura, seria impossível um levantamento exaustivo de obras que precedem os experimentos estéticos digitais na exploração dessa metáfora. Entre as mais assentes na academia como antecedentes explícitos da literatura eletrônica (RETTBERG, 2019), talvez possamos elencar os contos de Jorge Luís Borges e algumas iniciativas de membros do grupo Oulipo (os quais definiram a si próprios como ratos a tentarem escapar aos labirintos que eles mesmos constroem); no âmbito de precursores nas artes plásticas para imagens digitais de labirintos, chamamos a atenção para pinturas como Teseo e il minotauro (1510), do Maestro di Tavarnelle, ou litografias de Escher, como Ascending and descending (1960). 
de ler/ver quanto o de criar um texto revelam-se operações de design, ou de engenho, tais quais as do pai de ícaro, as de Andrei Tomaz, as dos usuários de sistemas hipermidiáticos, ou as de tantos quantos se aventurem diante do minotauro, monstro que só se combate por ações de dar forma à matéria insignificante e atribuir-lhe sentidos.

Às formas de escritura que demandam processos não triviais de leitura, como os poemas procedurais de Tavares (2010), Aarseth (1997) deu o nome de cibertextos, conceito que o autor emprega para tratar de romances hipertextuais no sistema Storyspace, ficções interativas, textos gerados por combinatória, $\mathrm{MUDs}^{4}$, games etc. Em seu livro destaca, porém, que um cibertexto não é necessariamente digital, dada a existência de obras impressas experimentais que exigiam, por procedimentos hipertextuais e/ou combinatórios, um esforço extra cognitivo (e, por vezes, físico), que Aarseth associou à leitura ergódica (1997). Com vistas a ressaltar características que distinguiriam o cibertexto de outros produtos culturais, o pesquisador faz uma ressalva ao discurso crítico que toma quaisquer narrativas como labirintos tão-somente porque exigem um percurso interpretativo por convolutas sendas.

Segundo Aarseth (1997), ainda que essa postulação seja coerente, ela se centra num tipo de labirinto popular nas artes visuais e arquitetônicas pré-Renascença: o labirinto unicursal, composto de um único caminho, o qual, tortuoso, se dobraria sobre si mesmo muitas vezes, obrigando o andarilho a uma série de curvas e voltas, como metáfora do pensamento meditativo e da leitura silenciosa. O que o teórico destaca é que um cibertexto, por outro lado, é um labirinto multicursal: repleto de entroncamentos de túneis, sua arquitetura defronta o leitor com bívios - pontos em que é preciso fazer escolhas, ou, em suas palavras, operações "não triviais" de leitura, de modo a selecionar (e, na sequência, ler) algumas sequências textuais atualizadas (scriptons) a partir de um universo potencial de várias outras (textons).

Também a travessia do labirinto, seja como desafio de encontrar uma saída em meio a tantas rotas (no caso de um labirinto multicursal), seja como prazer na deambulação contemplativa (no caso de um labirinto unicursal), pode ser abordada pelo viés da ludologia (GAZZARD, 2013). Jogos de toda a sorte envolvem a exploração de intrincados espaços topológicos em marcações

\footnotetext{
4 A sigla MUD pode se referir a variações da expressão multi-user dungeon (masmorra multiusuário), com a última letra indicando também os substantivos domain ou dimension (dimensão ou domínio). Em todos os casos, designa jogos de RPG para múltiplos participantes, os quais interagem por meio de uma interface textual.
} 
temporárias sobre o solo, em tabuleiros, em estruturas arquitetônicas em tamanho real, em construtos puramente mentais (no caso de muitos jogos de RPG orais), em almanaques impressos, em jogos de computador etc. Se, na terminologia de Hutcheon (2011), as artes visuais e a literatura, previamente referidas nesta seção, engendram labirintos pelos modos de engajamento do mostrar e do contar, respectivamente, os jogos fazem-no pelo modo do interagir. Assim, um jogador não é alguém que vê ou lê um labirinto, mas alguém que o vivencia e é por ele desafiado, frequentemente experimentando o sentimento de desorientação que a palavra inglesa maze (sinônima de labyrinth) e seu derivado amaze (estupefazer) conotam. A depender de contingências e possibilidades de cada mídia em que o ludo se desenrola, o jogador pode ser instanciado ${ }^{5}$ com uma visão do alto do labirinto, como Dédalo que pairasse sobre sua obra arquitetônica, ou de dentro de um de seus túneis, tal qual Teseu que avançasse por entre os bívios: diferença que os jogos de todas as épocas bem souberam explorar e, no mundo do entretenimento digital, talvez seja mais bem sintetizada no par Pacman e Doom.

Traços dessas representações prévias do labirinto em variadas mídias, como as artes plásticas, a literatura e os jogos, são retomados na obra digital de Andrei Thomaz, na qual a metáfora se reveste ainda das relações labirínticas que a hipermídia enseja. Nesse caso, se seu trabalho é por vezes tratado como webarte (DE LIMA-LOPES, 2019), gamearte (VARES; SANTOS, 2010), arte digital/eletrônica (NUNES, 2016), arte visual (THOMAZ, n.d.), somamos mais uma a essas nomenclaturas - a de tessitura eletrônica - , mas fazemo-lo mais a título de provocação do que de sistematização taxonômica. Afinal, o portfólio do artista, disponível em seu sítio web, mais funciona como um labirinto entre suas diferentes obras - e as diferentes linguagens que elas mobilizam - do que como um catálogo absoluto. Como fio de Ariadne que conectasse suas variadas obras e nos ajudasse a lê-las sem que nos perdêssemos no caminho, adotamos nesta análise a metáfora do labirinto, explorada de variadas maneiras pelo artista, conforme discutido na seção a seguir.

\section{De frente com o minotauro}

Mestre em Artes Visuais pela USP e formado em Artes Plásticas pela UFRGS, Andrei Thomaz é um premiado ${ }^{6}$ artista visual que também trabalha como

5 Ambas as perspectivas de representação também são possíveis nos modos do mostrar e do contar, mas, dado o caráter imersivo do modo do interagir, as diferenças de ponto de vista ganham outra dimensão no universo dos jogos.

6 A lista completa dos prêmios pode ser encontrada no site do artista (THOMAZ, n.d.). 
programador e é sócio do estúdio de produção digital Mandelbrot, baseado em São Paulo. Faz parte ainda do Grupo Poéticas Digitais, vinculado ao Departamento de Artes Plásticas da Escola de Comunicações e Artes da USP.

Em seu sítio web, junto com registros fotográficos de instalações e exposições já realizadas em espaços urbanos abertos e fechados - portas do labirinto que optamos por não tomar, a fim de garantir mais sistematicidade ao corpus deste artigo, restrito a três trabalhos de Thomaz —, encontramos links para criações puramente digitais, nas quais imagens técnicas fazem o que sabem de melhor: representam metáforas sem referentes, nos termos de Brunel (2000), dado que compõem símbolos visuais da ideia de labirinto, mas sem que haja de fato um elemento no mundo real no qual se baseiem.

Entre as criações digitais de Thomaz que apostam em relações intertextuais explícitas com a mitologia grega para a representação do labirinto, podemos destacar Dédalo e Ariadne, cuja segunda versão (única disponível atualmente na página do artista) consiste na justaposição horizontal de dois espaços quadrangulares; o da esquerda é a princípio um plano completamente branco, ao passo que o da direita se apresenta como um labirinto em preto e branco visto de cima. Logo após acessar a obra, o espectador vê progressivamente o desfazimento da imagem no espaço à direita e a simultânea composição de um novo labirinto à esquerda, dinâmica de que reproduzimos um instantâneo na Figura 1.

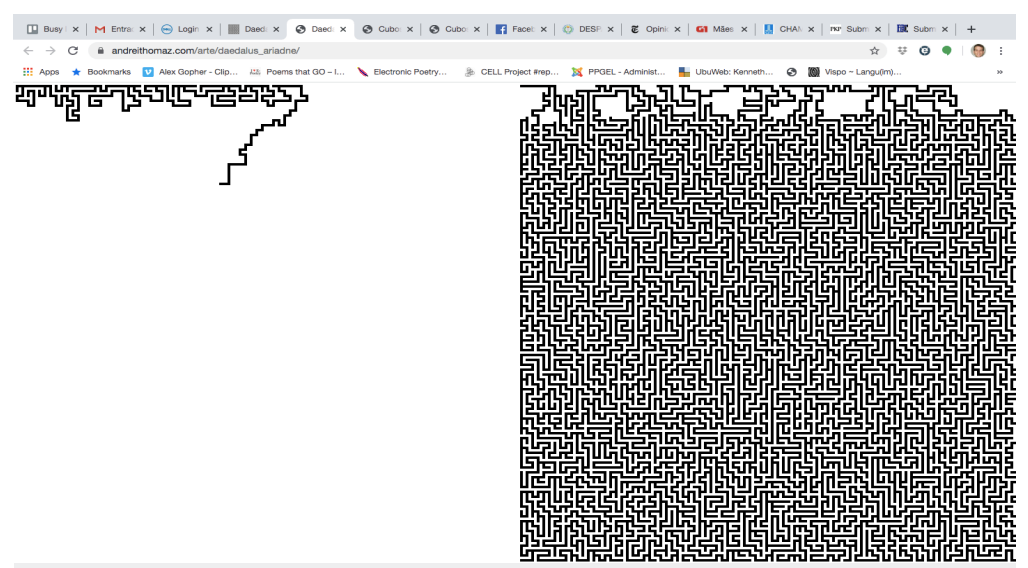

Fig. 1. Interface de Dédalo e Ariadne. Fonte: Thomaz (n.d.)

Para além da sedução óptica a que as imagens dinâmicas aqui conduzem, chama a atenção o fato de que, muito embora a obra remedeie (BOLTER; 
GRUSIN, 2000) para o digital um modelo de labirinto que é muito próximo dos passatempos em almanaques impressos, não se trata de um jogo: Dédalo e Ariadne é uma obra não interativa, posto que não abre espaço para qualquer intervenção material do usuário sobre o labirinto. A este cabe apenas ver o trabalho dos algoritmos generativos, que compõem diferentes traçados a cada iteração do sistema.

Tal qual Dédalo alado, o usuário paira acima dos labirintos da esquerda e da direita, podendo ver toda a sua extensão e o processo dialético de seu (des) fazimento; não tem, porém, a chance de enfrentá-los de dentro, isto é, de seguir suas trilhas, dada a velocidade em que as imagens se transformam. Como quem voasse acima do labirinto, sua esperança de fuga é apenas uma: fechar a aba do navegador em que a animação se desenrola - ou, em outras palavras, deixar o labirinto sem de fato percorrê-lo. Dado que a obra abre uma aba diferente quando a acessamos, não temos sequer a opção de clicar no browser em Voltar, gesto que Leão (2005) associa ao fio de Ariadne no universo da hipermídia, indicando um rumo retrógrado até determinado ponto de partida.

Por outro lado, mesmo que não vejamos a estrutura de dentro, como faria Teseu munido do fio de Ariadne, temos ainda uma relação metafórica visual que não pode ser desprezada: as linhas geométricas pretas que se formam no plano à esquerda e se apagam à direita podem ser lidas tanto conforme as convenções de representação gráfica das paredes de labirintos em papel, quanto como um fio negro que se (des)enrolasse à medida que o herói explora o espaço topológico. Na indecisão entre essas interpretações, temos as linhas ora como contingenciadoras, ora como norteadoras do movimento do herói, num jogo de trompe l'oeil' já aludido pelo título da obra, que relaciona personagens de episódios narrativos diferentes na mitologia grega Dédalo, que constrói o labirinto, como na imagem à esquerda, e Ariadne, que permite a escapada, como na imagem da direita — articulados pela arquitetura que encerra o minotauro.

A alusão ao monstro de corpo de homem e cabeça de touro - jogo de opostos como os demais que marcam qualquer labirinto, como dentro e

7 Ainda que no site de Thomaz (n.d.) se leia que Dédalo e Ariadne permite ver "os processos de construção e de solução de um mesmo labirinto, simultaneamente", parece-nos novamente haver aqui uma ilusão de óptica. Em vez da solução de um labirinto, que envolveria necessariamente traçar um percurso sem interrupções (como alguém que não tirasse a caneta do papel enquanto resolvesse um passatempo desse tipo em um almanaque), o que há são algoritmos de traçado e apagamento do labirinto, os quais por vezes pulam entre pontos desconexos da interface toda vez que uma linha geométrica desemboca num beco sem saída. 
fora, alto e baixo, unidade e multiplicidade etc. (BRUNEL, 2000) - também é significativa em A caça e o caçador (THOMAZ, n.d.); aliás, este é outro par de contrários que um labirinto pode engendrar. No caso dessa obra, outra remediação (BOLTER; GRUSIN, 2000) do universo dos jogos para as artes visuais se faz evidente, mas agora operando com uma linguagem dos games digitais.

Conforme se observa na Figura 2, o espectador tem, ao acessar essa obra na página do artista, a justaposição lateral de duas interfaces; em cada uma delas, acompanha-se a movimentação em primeira pessoa de uma câmera, avançando por partes diferentes de um mesmo labirinto. O fato de que ambas as câmeras representam segmentos do mesmo espaço topológico, ainda que separados por alguns bívios, é sugerido pela uniformidade das cores em uma paleta de cinza e pela sistemática angulação em noventa graus entre os planos das paredes, do teto e do piso em cada cena.

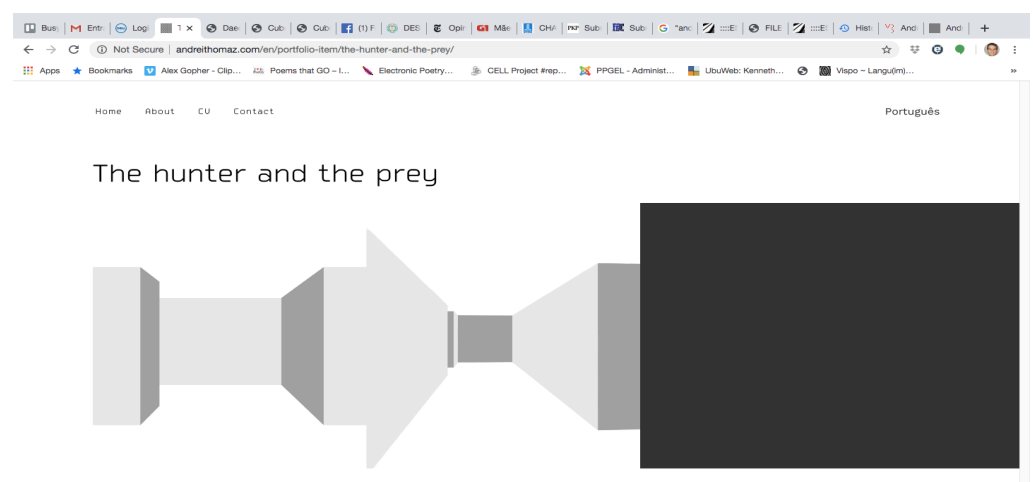

Fig. 2. Interface de $A$ caça e o caçador. Fonte: Thomaz (n.d.)

Desse modo, as personagens cuja mirada cada uma dessas interfaces simula acabam sendo sobredeterminadas mutuamente pelo espaço em comum que negociam enquanto exploram o labirinto, dinâmica amplificada pelo uso de termos cognatos para nomeá-las no título da obra. Trata-se, afinal, da caça e do caçador, personagens que se distinguem apenas por posições diferentes numa mesma rede, cujos nós se articulam pela dinâmica do caçar. Considerando que, nessa obra, as interfaces permitem visões de dentro dos túneis, e não do alto, como em Dédalo e Ariadne, estamos certos de aqui revisitar o mito pela perspectiva de Teseu e do minotauro, e não de Ícaro e seu pai. O que não se pode saber com certeza, no entanto, é quem é de fato a caça ou o caçador nessa obra: está o monstro à caça do herói, ou 
vice-versa? Mais um par opositivo se submete, então, a uma deriva rizomática, reticular, complexa, ou como queiram as demais metáforas labirínticas do pós-estruturalismo e do pós-modernismo.

Interessante ainda é notar que, enquanto as imagens em Dédalo e Ariadne paravam de ser executadas quando a metade esquerda da tela era totalmente preenchida por um novo labirinto, acompanhada pelo esvaziamento da imagem à direita, o clímax da narrativa de $A$ caça e o caçador é outro: quando uma das câmeras consegue encontrar sua antípoda e a encurrala. Nesse momento, suspende-se a animação e ambas as câmeras voltam ao ponto inicial, como se Teseu e o minotauro estivessem eternamente fadados a esse jogo de gato e rato, sem que o usuário possa intervir em nenhum momento, conquanto a interface seja muito semelhante a de jogos de tiro em primeira pessoa, como no clássico Doom, e portanto convide a um desejo não realizável de interação lúdica. Nesse modo do mostrar, e não do interagir (HUTCHEON, 2011), tudo o que podemos fazer é ver romper-se infinitamente o fio de Ariadne, para logo depois reiniciar-se seu desenrolar.

Ademais, o apelo a uma memória de outras experiências labirínticas é ainda maior se levarmos em conta que "o desenho do labirinto é similar ao construído para a gravação da cena final de O iluminado, de Stanley Kubrick (1980)" (THOMAZ, n.d.); que o recurso a cutscenes (ou a cenas de machinima - cinema com gráficos de jogos) é cada vez mais frequente nos games, alternando passagens a ver e a jogar; ou que a sensação de profundidade na animação é obtida por técnicas de perspectiva usadas desde a pintura renascentista, num curioso trocadilho com a ideia de ponto de fuga, muito embora em A caça e o caçador ninguém fuja com sucesso, enfim.

Tal trama intertextual vai se complexificando quando referências a outras narrativas, prolíficas em diferentes mídias, são evocadas no portifólio de Andrei Thomaz, como na animação disponível no link Biblioteca, dentro da página Pacman e o minotauro ${ }^{8}$, trabalho desenvolvido a partir de seu projeto de graduação em Artes Visuais, o qual explorava diferentes ressignificações desses dois personagens do imaginário do labirinto. 
Nesse sentido, curioso é pensar que, já na palavra que funciona como hiperlink para a obra, Biblioteca, temos uma metáfora altamente produtiva: uma biblioteca é, afinal, uma das imagens prototípicas das redes intertextuais, dado que se organiza pelas relações que diferentes livros contraem entre si num arquivo, extrapolando o mero acúmulo de unidades disjuntas. A cada nova obra que se acrescenta a uma biblioteca, todo o conjunto é ressignificado, numa articulação complexa de sentidos que em muito supera a soma das partes. Ademais, considerando-se o universo da programação de computadores - este no qual se desenrolam os labirintos das hipermídias (LEÃO, 2005) - , o signo biblioteca amplia seu escopo, porquanto nessa esfera discursiva também pode designar uma coleção de arquivos, módulos, scripts ou rotinas reutilizáveis na programação - um código intertextual, portanto.

Ambas as acepções de biblioteca são, pois, acionadas nesse trabalho de Thomaz, na medida em que, ao acessar o link, o usuário é redirecionado para uma animação envolvendo elementos gráficos reutilizados de outros trabalhos seus - as representações visuais pixeladas de Pacman e do minotauro - e, consequentemente, hibridizando seus universos narrativos. A associação entre biblioteca e texto é também aqui potencializada quando, ao longo do vídeo, a personagem do jogo Pacman se desloca pelos espaços em branco entre palavras de um parágrafo em inglês, extraído de Alice através do espelho, cuja tradução para o português apresentamos a seguir:

\footnotetext{
"Eu veria o jardim muito melhor", disse Alice a si mesma, "se pudesse chegar ao topo daquele morro, e cá está uma trilha que leva direto para lá... pelo menos - não, não tão direto..." (depois de seguir a trilha por alguns metros e dar várias viradas bruscas) "mas suponho que por fim chega lá. É interessante como se enrosca! Mais parece um saca-rolha que um caminho! Bem, esta volta vai dar no morro, suponho... não vai! Vai dar direto na casa de novo! Bem, neste caso vou tentar na direção contrária" (CARROLL, 2012, p. 149).
}

Em Alice no país das maravilhas e em Alice através do espelho são patentes as referências a jogos de toda sorte, como apostas de corrida, faz de conta, partidas de xadrez, adivinhas, cartas de baralho, desafios lógicos e labirintos. No excerto supracitado, a protagonista do romance de Carroll se perde num dédalo altamente recursivo, em busca de um caminho para um ponto de vista privilegiado para o jardim - este também um espaço para intrincados experimentos paisagísticos na Inglaterra vitoriana. 
Tal qual Alice perdida nos túneis desse labirinto e com apenas uma visão parcial do cenário, o usuário que assiste à animação de Biblioteca não pode ler na íntegra o parágrafo de Carroll. Em vez disso, apenas um pedaço do trecho é focalizado de cada vez pela câmera, como num zoom exagerado, deixando mais palavras de fora do que as que se dão a ver. Ler o trecho como geralmente se lê literatura se torna, então, impossível, e o que é material verbal em Carroll se torna signo icônico na obra de Andrei Thomaz. Nesse processo, as letras negras fazem as vezes de paredes que restringem o movimento de Pacman, que tem de se deslocar entre os espaços em branco, como se observa na Figura 3.

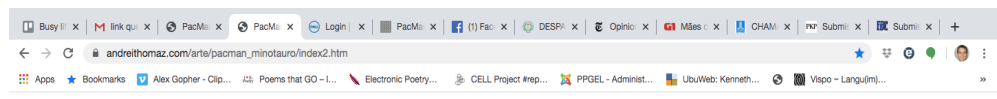

\section{$\therefore$ said Alice to II: and here's a ), it doesn't do tho noth and}

Se, nos entendimentos mais comuns do processo de interpretação textual, o leitor é concebido como alguém que se move pelas palavras do texto a fim de construir sua interpretação, como na metáfora do labirinto unicursal cujas limitações Aarseth (1997) destaca, em Biblioteca é pelos espaços e lacunas que se dá essa movência, talvez atualizando alguns dos pressupostos teórico-críticos da Estética da Recepção. Nesse labirinto multicursal pelos brancos entre as letras, Pacman vai avançando ora horizontal, ora verticalmente; enquanto isso, a mirada da câmera o acompanha, de modo a revelar outros trechos do excerto de Carroll, transformado de espaço narrativo verbal em cenário imagético digital. 
Ao fim da animação, as palavras do romance vitoriano dão lugar às letras que compõem o substantivo biblioteca, dispostas na tela na vertical, e junto a Pacman passa a se movimentar também uma representação gráfica do minotauro, de mesmas dimensões e estilo que a personagem anterior. Ambas permanecem se movendo em loop na tela quase toda branca, ora se afastando, ora se aproximando, numa dinâmica de caça e caçador que dispensa o fio de Ariadne, uma vez que as paredes de grafemas já não mais lá estão.

\section{Saindo do labirinto}

Ao longo deste artigo, observamos como a metáfora do labirinto, em íntima relação com outras imagens da complexidade e da interconexão, como a rede e o rizoma, é uma constante em diferentes obras do artista Andrei Thomaz, especialmente naquelas que aqui tomamos como objeto de análise: Dédalo e Ariadne, A caça e o caçador e Biblioteca. Tal corpus poderia, porém, ser estendido, em outras ocasiões, para abranger também trabalhos como Cubos de cor, Eclipses, Para desenhar com os olhos/Para percorrer com os olhos, Labirinto Zero, entre tantos outros, nos quais a mesma metáfora é mobilizada a partir de intrincados percursos que envolvem o universo dos games, das artes visuais e da literatura.

Nas obras analisadas neste artigo, percebemos uma evidente trama de conexões intertextuais e intermidiáticas, nas quais chamam mais atenção os movimentos de passagens entre esses discursos (MACHADO, 2010) do que uma suposta especificidade de cada linguagem artística. A metáfora do labirinto serviu-nos, pois, de fio de Ariadne com o qual pudéssemos deambular entre os trabalhos de Thomaz e os textos da cultura por eles evocados, mas sem que nos perdêssemos em demasia, de modo a podermos identificar um ponto de partida e um de chegada nesta reflexão (em meio a tantos outros percursos possíveis).

Visto que muitas dinâmicas hipermidiáticas se estruturam como labirintos (LEÃO, 2005), os quais replicam mesmo as arquiteturas do computador (WHITE, 1997) e do chip (MACHADO, 1997), uma análise mais detida de artes digitais que se debruçam sobre essa metáfora permite-nos compreender um pouco melhor a cibercultura e seus artefatos estéticos. Nestes, com frequência o usuário é convidado a experimentar os sentidos de desorientação e exploração que caracterizam o labirinto, sob a eterna ameaça de um minotauro, uma dúvida, uma disrupção interpretativa que só tornam o caminho mais interessante, enfim. 
Vinicius Carvalho Pereira é professor do Departamento de Letras e do Programa de Pós-Graduação em Estudos de Linguagem da UFMT e doutor em Ciência da Literatura pela UFRJ.

viniciuscarpe@gmail.com

\section{Referências}

AARSETH, E. Cybertext: Perspectives on Ergodic Literature. Baltimore: Johns Hopkins University Press, 1997.

BOLTER, J. D.; GRUSIN, R. Remediation: Understanding New Media. Cambridge: MIT Press, 2000.

BRUNEL, P. Dicionário de mitos literários. Rio de Janeiro: José Olympio, 2000.

CARROLL, L. Alice no país das maravilhas/Através do espelho. Tradução de Maria Luiza X. de A. Borges. Rio de Janeiro: Zahar, 2012.

. Through the Looking Glass, and What Alice Found There. Los Angeles: Enhanced Media, 2017.

DE LIMA-LOPES, R. E. Arte e tecnologia. São Paulo: SENAC, 2019.

DELEUZE, G.; GUATTARI, F. Mil platôs. Capitalismo e esquizofrenia, v 1. Rio de Janeiro: Editora 34, 1997.

GAZZARD, A. Mazes in Videogames: Meaning, Metaphor and Design. Jefferson: McFarland \& Company, 2013.

HUTCHEON, L. Uma teoria da adaptação. Florianópolis: UFSC, 2011.

KRISTEVA, J. Introdução à semanálise. São Paulo: Perspectiva, 1969.

LEÃO, L. O labirinto da hipermídia: arquitetura e navegação no ciberespaço. São Paulo: Iluminuras, 2005.

MACHADO, A. Arte e mídia. Rio de Janeiro: Jorge Zahar, 2010.

. Hipermídia: o labirinto como metáfora. In: DOMINGUES, D. (org.). A arte no século XXI: a humanização das tecnologias. São Paulo: Fundação Editora da UNESP, 1997.

MOREIRA, M. E. R. Textos em rede, labirintos literários. Revista Brasileira de Literatura Comparada. Niterói, v. 14, n. 20, 2012.

MORIN, E. Introdução ao pensamento complexo. Porto Alegre: Sulina, 2007.

MUSSO, P. A filosofia da rede. In: PARENTE, A. (Org.). Tramas da rede: novas dimensões 
filosóficas, estéticas e políticas da comunicação. Porto Alegre: Sulina, 2004.

NUNES, F. O. O tempo nas obras de Andrei Thomaz: por uma linguagem algorítmica. 2016. Disponível em: <http://www.musarara.com.br/por-uma-linguagem-algoritmica>. Acesso em: 30 abr. 2020.

RETTBERG, S. Electronic Literature. Cambridge: Polity, 2019.

SNYDER, L. Hypertext: the Electronic Labyrinth. New York: NYU Press, 1997.

TAVARES, O. G. A interatividade na poesia digital. 2010. 120 fl. Dissertação (Mestrado em Literatura). Programa de Pós-Graduação em Literatura, Universidade Federal de Santa Catarina, Florianópolis, 2010.

THOMAZ, A. Site do artista. n.d. Disponível em: <https://andreithomaz.com/>. Acesso em: 30 abr. 2020.

VARES, M. F.; SANTOS, N. C. Artistas contemporâneos no RS: arte, tecnologia e mídias digitais. Anais da $25^{a}$ Jornada Acadêmica Integrada. Santa Maria: UFSM, 2010. Disponível em: <https://portal.ufsm.br/jai2010/anais/trabalhos/trabalho_1041284738.htm>. Acesso em: 30 abr. 2020.

WHITE, N. T. A casa dos espelhos. In: DOMINGUES, D. (org.). A arte no século XXI: a humanização das tecnologias. São Paulo: Fundação Editora da UNESP, 1997.

Artigo recebido em 28/04/2020 e aprovado em 24/06/2020. 